Araş̦tırma Makalesi

\title{
1956 İstanbul Dünya Kupası Güreş Müsabakalarında Türkiye
}

Mehmet YILDIZ ${ }^{1}$

\author{
Özbay GÜVEN ${ }^{2}$
}

\author{
Efdal Utku GÜVEN ${ }^{3}$
}

\section{$\ddot{\mathbf{O z}}$}

Bu çalışmanın amacı, 1956 yılında İstanbul'da düzenlenen Dünya Kupası Serbest ve Greko-Romen Güreş Şampiyonalarında Türk Güreș Millî Takımlarının elde ettiği başarıları değerlendirmektir. Bu amaçla nitel araştırma yöntemlerinden döküman incelemesi yöntemi kullanılmıştır. Bulgulara ulaşmak amacıyla 1956 yılında İstanbul'da düzenlenen Dünya Kupası'na yönelik detaylı literatür taraması yapılmış ve elde edilen veriler üzerinden içerik analizi yapılmıştır. Araştırma sonuçlarına göre Türk Serbest Güreş Millî Takımı sporcuları dört altın, iki gümüș ve iki bronz madalya kazanarak 42 puan toplamıș ve dönemin en güçlü takımlarından olan Rus güreş takımını geride bırakarak takım halinde birinci olmuştur. Türk Grekoromen Güreş Millî Takımı sporcuları ise iki altın, üç gümüş ve bir bronz madalya kazanarak 36,5 puan toplayarak takım halinde ikinci olarak önemli bir başarıya imza atmışlardır. Türk güreş millî takımlarının elde ettiği bu başarılar Dünya Kupası Güreş Şampiyonasının ilk kez 1956 yılında İstanbul'da düzenlenmiş olması ve ilk kez düzenlenen böyle bir organizasyonda elde edilen başarılar açısından hem Türk güreş tarihi hem de dünya güreş tarihinde son derece önemli olarak görülmektedir. Bu organizasyon ayrıca Türk güreşçiler Hüseyin Akbaş ve Mustafa Dağıstanlı’nın 1954 yılında Tokyo'da düzenlenen Dünya Serbest Güreş Şampiyonası’ndan sonra 1956 yılında İstanbul'da düzenlenen Dünya Kupası'nda da altın madalya kazanma başarısını gösterdiği bir organizasyon olmuştur.

Anahtar Kelimeler: Güreş, Dünya Kupası, İstanbul, Türkiye.

\section{Istanbul World Cup Wrestling Competition In Turkey}

\begin{abstract}
The aim of this study is to evaluate the achievements of Turkish Wrestling National Teams in the World Cup Free and Greco-Roman Wrestling Championships held in Istanbul in 1956. For this purpose, document analysis method, one of the qualitative research methods, was used. In order to reach the findings, a detailed literature search was made for the World Cup held in Istanbul in 1956 and content analysis was made on the data obtained. According to the results of the research, Turkish Free Wrestling National Team athletes won four gold, two silver and two bronze medals and collected 42 points, leaving behind the Russian wrestling team, which was one of the strongest teams of the period, and ranked first in a team. Turkish Greco-Roman Wrestling National Team athletes, on the other hand, won two gold, three silver and one bronze medals and collected 36.5 points and achieved a significant success as a team. These achievements of Turkish wrestling national teams are considered to be extremely important both in Turkish wrestling history and in the history of world wrestling in terms of the fact that the World Cup Wrestling Championship was first held in Istanbul in 1956 and the successes achieved in such an organization for the first time. This organization was also an organization where Turkish wrestlers Hüseyin Akbaş and Mustafa Dağıstanlı succeeded in winning the gold medal in the World Cup held in Istanbul in 1956 after the World Free Wrestling Championship in Tokyo in 1954.
\end{abstract}

\footnotetext{
${ }^{1}$ Sorumlu Yazar:Gazi Üniversitesi, Spor Bilimleri Fakültesi, Ankara, Türkiye, mehmetyildiz@gazi.edu.tr, https://orcid.org/0000-0001-9784-6050

${ }^{2}$ Gazi Üniversitesi, Spor Bilimleri Fakültesi, Ankara, Türkiye, ozbay@ gazi.edu.tr , https://orcid.org/0000-0002-4024-6789

${ }^{3}$ Anadolu Üniversitesi, Açıköğretim Fakültesi, Sosyoloji Bölümü, Eskişehir, Türkiye, efdalguven@gmail.com , https://orcid.org/0000-0002-5237-2290
} 
Keywords: Wrestling, World Cup, Istanbul, Turkey.

\section{GİRIŞ}

Türkiye, Cumhuriyetin ilan edilmesi ile birlikte her alanda olduğu gibi spor alanında da uluslararası arenada kendisini göstermek istemiş ve bu amaçla farklı spor organizasyonlarına katılmıştır. Türkiye bu organizasyonların bazılarında sadece katılımc1 olurken, bazı şampiyonaların organizasyonunu üstlenerek önemli bir vizyon üstlenmiştir. $\mathrm{Bu}$ organizasyonlardan bir tanesi de 1956 yılında İstanbul'da düzenlenen Dünya Kupası Güreş Şampiyonası olmuştur. Dünya güreş tarihi incelendiğinde Dünya Kupalarının ilk kez 1956 yılında düzenlenmeye başladığ1 görülürken, 1958 yılında Bulgaristan'ın Sofya kentinde düzenlenen Dünya Kupası'ndan sonra organizasyona 1973 y1lına kadar ara verilmiştir. 1973 y1lında tekrar düzenlenmeye başlayan Dünya Kupası Güreş Şampiyonaları günümüze kadar düzenli olarak yapılmaya devam etmiştir.

$\mathrm{Bu}$ araştırma ile Dünya Kupası Güreş Şampiyonasının ilk kez Türkiye'de düzenlenmiş olması ve bu şampiyonada Türk sporcuların elde ettiği başarıların değerlendirilmesi oldukça önemli görülmektedir (Dünya Kupası Şampiyonaları Sonuçları, 2020). Ayrıca 1956 yılında düzenlenen Dünya Kupas1 Serbest ve Grekoromen Güreş Şampiyonalarının daha önce hiç çalışılmamış olması nedeniyle bütün detaylarıyla ele alınması, dönemin Türk güreş tarihine ve Dünya güreş tarihine 1şı tutması açısından da önemli görülmektedir.

\section{Araştırmanın Amacı}

$\mathrm{Bu}$ çalışmanın amacı, 1956 yılında İstanbul'da düzenlenen Dünya Kupası Serbest ve Greko-Romen Güreş Şampiyonalarında Türk Güreş Millî Takımlarının elde ettiği başarıları değerlendirmektir.

\section{YÖNTEM}

$\mathrm{Bu}$ araştırma, Doküman incelemesi yöntemi esas alınarak hazırlanmıştır. Araştırma bulgularına ulaşmak için ayrıntılı literatür araştırması yapılmış, elde edilen bulgular üzerinden oluşturulan kategori ve kodlarla elde edilen veriler kendi içerisinde sınıflandırılmıştır. Veri toplama ve analiz işlemlerinde verilerin kendi içinde anlaml olmalarına dikkat edilmiştir. $\mathrm{Bu}$ doğrultuda çalışmanın amacı, veri toplama aracı ve veri analizi arasındaki tutarlık sürekli göz önünde bulundurulmuştur.

\section{BULGULAR}

Türkiye, 25-31 Mayıs 1956 tarihleri arasında İstanbul'da düzenlenen Dünya Kupası Güreş Şampiyonları hazırlıklarına İstanbul, Moda'da bulunan tesislerde başlamıştır. Türk güreşçiler şampiyona için hazırlıklarına yoğun bir şekilde devam ederken, organizasyon komiteside gelen kafilelerin konaklama ve diğer ihtiyaçları için çalışmalara ağırlık vermiş, şampiyona için Mithatpaşa Stadyumu'na portatif minderler kurulmuştur. Ayrıca Türk güreş takımlarının belirlenmesi için kamp süresince seçmeler yapılmıştır (Milli Güreş Kampında Son Hazırlık. (1956, Mayıs 15). Milliyet Gazetesi, s.6, sü. 8).

Şampiyona öncesi millî takım kamp hazırlıkları ile birlikte organizasyon komitesinin çalışmalarıda oldukça titiz bir şekilde devam etmiştir. $\mathrm{Bu}$ süreci değerlendiren dönemin Güreş Federasyonu Başkanı Vehbi Emre şampiyona ve Türk güreşçiler ile ilgili şunları söylemiştir; "Millî takimin kampta bulunan ve iyi bir şekilde hazırlanma imkanını bulduğunu tahmin ettiğimiz elemanlar arasindan bizi en iyi şekilde temsil edebilecek güreşçileri seçeceğiz. Türkiye'yi temsil edecek gençleri aralarında hiç tereddüt kalmayacak şekilde ayırmak başlıca hedefimizdir." (Güreş Ekibinin Tespit Tarihi Henüz Belli Değil. (1956, Mayıs 17). Milliyet Gazetesi, s.6, sü. 5-8).

Bütün bu hazırl1klar devam ederken, FILA (Federation Internationale des Luttes Associes/Uluslararası Amatör Güreş Federasyonu) tarafindan organizasyon öncesinde delegelerin katılımıyla bir teknik kurul toplantısı düzenlenmiştir. Bu toplantıya FILA Başkanı Fransız Roger Coulon'un yanı sira Türkiye, Misır, Hollanda, Rusya ve Finlandiyalı üyeler katılmış ve 1956 
Melbourne Olimpiyat Oyunları'nda uygulanacak kuralların değerlendirilmesi ve Türkiye Güreş Federasyonu'nun güreşlerin dört devreden 12 dakika olması ve güreş müsabakalarında beraberlik sonucununda gelmesi teklifleri teknik komisyonca değerlendirilerek FILA kongresinde görüşülmesine karar verilmiştir (Takımların Kadroları Dün Tespit Edildi. (1956, Mayıs 19). Milliyet Gazetesi, s.6, sü. 6-8; Güreş Müsabakalarının 12 Dakikaya İnmesi Teklifimizi Dün Teknik Komite Müsait Karşıladı. (1956, Mayıs 23). Hürriyet Gazetesi, s.6, sü.4-5).

25 Mayıs 1956 tarihinde başlayacak Dünya Kupas1 müsabakalarına katılacak takımlar şampiyona öncesi İstanbul'a gelirken, 22 Mayıs 1956 tarihinde yapılan son seçme ile hazırlıklarını tamamlayan Türk Güreş Millî Takımı nihai halini almıştır. Yapılan bu seçme sonrası Türkiye'yi Dünya Kupası Serbest ve Grekoromen Güreş Şampiyonaları'nda temsil edecek Türk Güreş Millî Takımları şu isimlerden oluşmuştur (Millî Güreş Takımımız Nihayet Tespit Edildi. (1956, Mayıs 22). Milliyet Gazetesi, s.6, sü. 1-6).

Tablo 1. 1956 Dünya Kupası Güreş Şampiyonaları Millî Takım Kadrosu

\begin{tabular}{|c|c|c|c|}
\hline Kilo & $\begin{array}{l}\text { Serbest } \\
\text { Güreş } \\
\text { Takım }\end{array}$ & Kilo & $\begin{array}{l}\text { Grekoromen } \\
\text { Güreş Takımı }\end{array}$ \\
\hline Antrenör & Celâl Atik & Antrenör & Celâl Atik \\
\hline $52 \mathrm{~kg}$ & $\begin{array}{l}\text { Hüseyin } \\
\text { Akbaş }\end{array}$ & $52 \mathrm{~kg}$ & $\begin{array}{ll}\begin{array}{l}\text { Dursun } \\
\text { Erbaş }\end{array} & \text { Ali } \\
\end{array}$ \\
\hline $57 \mathrm{~kg}$ & $\begin{array}{l}\text { Mustafa } \\
\text { Dağ } 1 \text { istanl1 }\end{array}$ & $57 \mathrm{~kg}$ & Yaşar Yılmaz \\
\hline $62 \mathrm{~kg}$ & $\begin{array}{l}\text { Bayram } \\
\text { Şİt }\end{array}$ & $62 \mathrm{~kg}$ & $\begin{array}{l}\text { Osman } \\
\text { Kanbur }\end{array}$ \\
\hline $67 \mathrm{~kg}$ & $\begin{array}{l}\text { Mehmet } \\
\text { Çelebi }\end{array}$ & $67 \mathrm{~kg}$ & Riza Doğan \\
\hline $73 \mathrm{~kg}$ & $\begin{array}{l}\text { İbrahim } \\
\text { Zengin }\end{array}$ & $73 \mathrm{~kg}$ & $\begin{array}{l}\text { Mithat } \\
\text { Bayrak }\end{array}$ \\
\hline $79 \mathrm{~kg}$ & İsmet Atl1 & $79 \mathrm{~kg}$ & İsmet Atl1 \\
\hline $87 \mathrm{~kg}$ & Adil Atan & $87 \mathrm{~kg}$ & Adil Atan \\
\hline $\begin{array}{l}\text { Ağır } \\
\text { S1klet }\end{array}$ & $\begin{array}{l}\text { Hamit } \\
\text { Kaplan }\end{array}$ & $\begin{array}{l}\text { Ağır } \\
\text { Siklet }\end{array}$ & $\begin{array}{l}\text { Hamit } \\
\text { Kaplan }\end{array}$ \\
\hline
\end{tabular}

Şampiyona öncesi şampiyonaya katılacak ülkelere İstanbul'a gelişleri öncesi 10 Mayıs 1956 tarihine kadar kafile listelerini gönderebilmelerine olanak sağlanırken, kafile listelerini gönderen ülkeler müsabakalardan bir kaç gün önce İstanbul'a gelerek hazırlıklarını sürdürmüşlerdir (Mısır ve Bulgar Güreşçileri Geliyor. 1956, Mayıs 8). Milliyet Gazetesi, s.6, sü.3). İlk kez düzenlenen Dünya Kupası Güreş Şampiyonası 25 Mayı 1956 tarihinde saat 16:00'da Mithatpaşa Stadı'nda yapılan merasim ile başlamıştır. Serbest stilde 12 ülkeden 61 güreşçinin katıldığg ve yirmi bin seyircinin izlediği açılış esnasında Maarif Vekili Ahmet Özel ve FILA Başkanı Roger Coulon'un konuşmaları sonrası yapılan kura çekimi ile serbest stil müsabakaları başlamıştır (Dünya Kupası. (1956, May1s 26). Milliyet Gazetesi, s.6, sü.1-7; https://www.wikiwand.com/en/1956_Wrestlin g_World_Cup).

Yapılan merasim sonrası başlayan güreşlerde $52 \mathrm{~kg}$ serbest stilde mücadele eden Türk güreşçi Hüseyin Akbaş, birinci turda Japon Kazmo Jida'y1 ve (Gündüz Yapılan Güreşler. (Güreş. (1956, Mayıs 26). Hürriyet Gazetesi, s. 6, sü. 1-8) ikinci turda İtalyan Chinazzo Luigi'yi sayıyla yenmiştir (Dünya Kupası. (1956, Mayıs 26). Milliyet Gazetesi, s.6, sü.17). Hüseyin Akbaş üçüncü turda İranlı Rauyut Pana'y1 tuşla (Şampiyonluğu Garantiledik. (1956, Mayıs 27). Hürriyet Gazetesi, s.6, sü.26) ve final müsabakasında Rus Mirian Tsalkalamanidze'yi de tuşla yenerek 1956 Dünya Kupası'nda şampiyon olmuştur. (Milli Güreş Takımızı (Serbest Güreşte Takımımız Dünya Şampiyonluğunu Aldı. (1956, Mayıs 28). Hürriyet Gazetesi, s.1, sü. 5-8). 52 kg'da madalya sıralaması aşağıdaki şekilde gerçekleşmiştir (Millî Güreş Takımımız Dünya Şampiyonu. (1956, Mayıs 28). Cumhuriyet Gazetesi, s.1, sü.5-8).

Tablo 2. 1956 Dünya Kupası Serbest Stil 52 kg Madalya Siralaması

\begin{tabular}{lll}
\hline Sıralama & Adı Soyadı & Ülke \\
\hline 1 & Hüseyin Akbaş & Türkiye \\
2 & Mirian Tsalkalamanidze & Rusya \\
3 & Kazmo Jida & Japonya \\
\hline
\end{tabular}

1956 Dünya Kupas1 $57 \mathrm{~kg}$ serbest stilde mücadele eden Türk güreşçi Mustafa Dağıstanl1, birinci turda İranlı Cabbar Bayram'1 sayıyla (Güreş. (1956, Mayıs 26). Hürriyet Gazetesi, s.6, sü.2-6), ikinci turda Polonyalı Trojanovski'yi tuşla yenmiştir (Dünya Kupas1. (1956, Mayıs 26). Milliyet Gazetesi, s.6, sü.1-7). Mustafa Dağıstanlı 
üçüncü turda Rus Alexandre Maissuradze'yi tuşla (Şampiyonluğu Garantiledik. (1956, Mayıs 27). Milliyet Gazetesi, s.6, sü.2-6), final müsabakasinda da Japon Jisuka Minoru'yu tuşla yenerek 1956 Dünya Kupası'nda şampiyon olmuşur (Serbest Güreşte Takımımız Dünya Şampiyonluğunu Ald1. (1956, Mayıs 28). Hürriyet Gazetesi, s.1, sü. 5-8). $57 \mathrm{~kg}$ 'da sıralama aşağıdaki şekilde gerçekleşmiştir (Millî Güreş Takımımız Dünya Şampiyonu. (1956, Mayıs 28). Cumhuriyet Gazetesi, s.1, sü.5-8).

Tablo 3. 1956 Dünya Kupası Serbest Stil 57 kg Madalya Siralaması

\begin{tabular}{lll}
\hline Sıralama & Adı Soyadı & Ülke \\
\hline 1 & Mustafa Dağıstanlı & Türkiye \\
2 & Cabbar Bayram & İran \\
3 & Jisuka Minoru & Japonya \\
\hline
\end{tabular}

1956 Dünya Kupası $62 \mathrm{~kg}$ serbest stilde mücadele eden Türk güreşçi Bayram Şit, birinci turda İranlı T. Hamid'i tuşla ve (Dünya Kupası Güreşleri Başladı. (1956, Mayıs 26). Cumhuriyet Gazetesi, s.6, sü.1-8) ikinci turda Fransız Georges Ballery'i tuşla yenmiştir (Şampiyonluğu Garantiledik. (1956, Mayıs 27). Milliyet Gazetesi, s. 6, sü.2-6). Bayram Şit üçüncü turda Rus Sinar Salimouline'ye sayı ile yenilmiş (Şampiyomluğu Garantiledik. (1956, May1s 27). Milliyet Gazetesi, s.6, sü.2-6), final müsabakasında ise Japon Shozo Sasahara'y1 sayıla yenerek 1956 Dünya Kupası'nı üçüncü sırada tamamlamıştır (Serbest Güreşte Takımımız Dünya Şampiyonluğunu Aldı. (1956, Mayıs 28). Hürriyet Gazetesi, s.1, sü. 5-8). 62 kg'da sıralama aşağıdaki şekilde gerçekleşmiştir (Millî Güreş Takımımız Dünya Şampiyonu. (1956, Mayıs 28). Cumhuriyet Gazetesi, s.1, sü.5-8).

Tablo 4. 1956 Dünya Kupası Serbest Stil 62 kg Madalya Siralamasi.

\begin{tabular}{lll}
\hline Siralama & Adı Soyadı & Ülke \\
\hline 1 & Shozo Sasahara & Japonya \\
2 & Sinar Salimouline & Rusya \\
3 & Bayram Şit & Türkiye \\
\hline
\end{tabular}

1956 Dünya Kupası $67 \mathrm{~kg}$ serbest stilde mücadele eden Türk güreşçi Mehmet Çelebi, birinci turda Macar Gyula Toth sayiyla (Gündüz Yapılan Güreşler. (1956, Mayıs 26). Hürriyet Gazetesi, s. 6, sü. 1-8) ve ikinci turda Lübnanlı Halil Nazım'1 tuşla yenmiştir
(Şampiyonluğu Garantiledik. (1956, May1s 27). Milliyet Gazetesi, s.6, sü.2-6). Mehmet Çelebi üçüncü turda İranlı Habibi Elmamalı'yı tuşla yenmiş (Dünkü Güreşlerde 12 Galibiyet Aldık. (1956, Mayıs 27). Cumhuriyet Gazetesi, s.5, sü.2-5), final müsabakasında Bulgar Georgi Zaitehev'e sayıyla yenilmiş ve 1956 Dünya Kupasını üçüncü sırada tamamlamıştır (Serbest Güreşte Takımımız Dünya Şampiyonluğunu Aldı. (1956, Mayıs 28). Hürriyet Gazetesi, s.1, sü. 5-8). $67 \mathrm{~kg}$ 'da sıralama aşağıdaki şekilde gerçekleşmiştir (Millî Güreş Takımımız Dünya Şampiyonu. (1956, Mayıs 28). Cumhuriyet Gazetesi, s.1, sü.5-8).

Tablo 5. 1956 Dünya Kupası Serbest Stil 67 kg Madalya Siralaması

\begin{tabular}{lll}
\hline Siralama & Adı Soyad1 & Ülke \\
\hline 1 & Bostaev Alimbeg & Rusya \\
2 & Georgi Zaitehev & Bulgaristan \\
3 & Mehmet Çelebi & Türkiye \\
\hline
\end{tabular}

1956 Dünya Kupas1 $73 \mathrm{~kg}$ serbest stilde mücadele eden Türk güreşçi İbrahim Zengin, birinci turda Polonya'dan Miroslaw Zywczyk sayı ile (Dünya Kupası. (1956, May1s 26). Milliyet Gazetesi, s.6, sü.1-7) ve ikinci turda Bulgar Murtaza Murtazof'u sayı ile yenmiştir. İbrahim Zengin üçüncü turda İsviçre'den Burgman'1 tuşla (Şampiyonluğu Garantiledik. (1956, May1s 27). Milliyet Gazetesi, s.6, sü.26) ve final müsabakasında Alman Horst Hoffman'1 tuşla yenerek 1956 Dünya Kupası'nda şampiyon olmuştur (Serbest Güreşte Takımımız Dünya Şampiyonluğunu Ald1. (1956, Mayıs 28). Hürriyet Gazetesi, s.1, sü. $5-8) .73 \mathrm{~kg}$ 'da sıralama aşağıdaki şekilde gerçekleşmiştir (Millî Güreş Takımımız Dünya Şampiyonu. (1956, Mayıs 28). Cumhuriyet Gazetesi, s.1, sü.5-8).

Tablo 6. 1956 Dünya Kupası Serbest Stil 73 kg Madalya Siralaması.

\begin{tabular}{lll}
\hline Siralama & Adı Soyadı & Ülke \\
\hline 1 & İbrahim Zengin & Türkiye \\
2 & Murtaza Murtazof & Bulgaristan \\
3 & Horst Hoffman & Almanya \\
\hline
\end{tabular}

1956 Dünya Kupas1 $79 \mathrm{~kg}$ serbest stilde mücadele eden Türk güreşçi İsmet Atl, birinci turda Bulgar Nikola Nikolov'u tuşla (Dünya Kupas1. (1956, Mayıs 26). Milliyet Gazetesi, s.6, sü.1-7) ve ikinci turda İtalyan 
Lepri'yi yine tuşla yenmiştir. İsmet Atlı üçüncü turda Rus Skhirtladze'yi sayıyla yenmiş (Şampiyomluğu Garantiledik. (1956, Mayıs 27). Milliyet Gazetesi, s.6, sü.2-6) ve final müsabakasinda Japon Kazuo Katsuramota'yı da tuşla yenerek 1956 Dünya Kupası'nda şampiyon olmuştur (Spor Haberleri. (1956, Mayıs 28). Hürriyet Gazetesi, s.6, sü. 1-8). 79 kg'da siralama aşağıdaki şekilde gerçekleşmiştir (Millî Güreş Takımımız Dünya Şampiyonu. (1956, Mayıs 28). Cumhuriyet Gazetesi, s.1, sü.5-8).

Tablo 7. 1956 Dünya Kupası Serbest Stil 79 kg Madalya Siralamas1

\begin{tabular}{lll}
\hline Siralama & Adı Soyadı & Ülke \\
\hline 1 & İsmet Atl1 & Türkiye \\
2 & Nikola Nikolov & Bulgaristan \\
3 & Kazuo Katsuramota & Japonya \\
\hline
\end{tabular}

1956 Dünya Kupas1 $87 \mathrm{~kg}$ serbest stilde mücadele eden Türk güreşçi Adil Atan, birinci turda İranl1 Nouri Hossein'1 tuşla (Dünya Kupas1. (1956, Mayıs 26). Milliyet Gazetesi, s.6, sü.1-7) ve ikinci turda İsviçre'den Holtzer'i sayı ile yenmiştir. Adil Atan üçüncü turda Macar Kovac'1 tuşla (Şampiyomluğu Garantiledik. (1956, May1s 27). Milliyet Gazetesi, s.6, sü.2-6) ve final müsabakasında Rus Boris Koulaev'i tuşla yenmiş ve 1956 Dünya Kupası'nda şampiyon olmuştur (Serbest Güreşte Takımımız Dünya Şampiyonluğunu Aldı. (1956, Mayıs 28). Hürriyet Gazetesi, s.1, sü. 5-8). 87 kg'da sıralama aşağıdaki şekilde gerçekleşmiştir (Millî Güreş Takımımız Dünya Şampiyonu. (1956, Mayis 28). Cumhuriyet Gazetesi, s.1, sü.5-8).

Tablo 8. 1956 Dünya Kupası Serbest Stil 87 kg Madalya Siralamas1

\begin{tabular}{lll}
\hline Siralama & Adı Soyad1 & Ülke \\
\hline 1 & Adil Atan & Türkiye \\
2 & Boris Koulaev & Rusya \\
3 & Nouri Hossein & İran \\
\hline
\end{tabular}

1956 Dünya Kupası Ağır s1klet serbest stilde mücadele eden Türk güreşçi Hamit Kaplan, birinci turda İranlı Muhammedi'yi tuşla (Dünya Kupası. (1956, Mayıs 26). Milliyet Gazetesi, s.6, sü.1-7) ve ikinci turda Bulgar Jussein Mehmedov'u tuşla yenmiştir (Gündüz yapılan güreşler. (1956, Mayıs 27). Hürriyet
Gazetesi, s. 6, sü. 1-8). Hamit Kaplan final müsabakasında Rus Arsene Mokokichvili'yi de sayıla yenerek 1956 Dünya Kupası'nda şampiyon olmuştur. Ağır sıklette sıralama aşağıdaki şekilde gerçekleşmiştir (Millî Güreş Takımımız Dünya Şampiyonu. (1956, Mayıs 28). Cumhuriyet Gazetesi, s.1, sü.5-8).

Tablo 9. 1956 Dünya Kupası Serbest Stil Ağır Siklet Madalya Siralamas1

\begin{tabular}{lll}
\hline Siralama & Ad1 Soyadı & Ülke \\
\hline 1 & Hamit Kaplan & Türkiye \\
2 & Arsene Mokokichvili & Rusya \\
3 & Jussein Mehmedov & Bulgaristan \\
\hline
\end{tabular}

1956 Dünya Kupası serbest stil müsabakalar sonrasinda Türkiye 44 puan toplayarak takım halinde şampiyon olurken, ülke puan sıralaması aşağıdaki şekilde gerçekleşmiştir (Serbest Güreşte Takımımız Dünya Şampiyonluğunu Aldı. (1956, Mayıs 28). Hürriyet Gazetesi, s.1, sü. 5-8).

Tablo 10. 1956 Dünya Kupası Serbest Stil Müsabakaları Sonrası Oluşan Ülke Puan Siralamas1

\begin{tabular}{lll}
\hline Sira & Ülke & Puan \\
\hline 1 & Türkiye & 44 \\
2 & Rusya & 31,5 \\
3 & Bulgaristan & 25,5 \\
4 & İran & 18,5 \\
5 & Japonya & 18 \\
6 & İtalya & 6,5 \\
7 & İsviçre & 6,5 \\
8 & Almanya & 6 \\
9 & Macaristan & 6 \\
10 & Fransa & 5 \\
11 & Polonya & 0,5 \\
\hline $25-28$ & Mayıs 1956 tarihi
\end{tabular}

25-28 Mayıs 1956 tarihleri arasında Mitatpaşa Stadı'nda düzenlenen Dünya Kupası serbest stil müsabakalarının ardından Dünya Kupası Grekoromen Güreş Müsabakaları 29 Mayıs 1956 tarihleri arasında Mitatpaşa Stadı'nda başlamıştır (Grekoromen Şampiyonası Bugün 16:30'da Başlıyor. (1956, Mayıs 29). Dünya Gazetesi, s.6, sü.1-8). Dünya Kupasına grekoromen stilde 16 ülkeden 89 güreşçi katılmıştır

(https://www.wikiwand.com/en/1956_Wrestli ng_World_Cup).

1956 Dünya Kupası $52 \mathrm{~kg}$ grekoromen stilde mücadele eden Türk güreşçi Dursun Ali Erbaş, birinci turda Lübnanlı Ahmet Nahli'yi tuşla (Spor Haberleri. (1956, Mayıs 30). 
Hürriyet Gazetesi, s.6, sü. 1-8) ve ikinci turda Fransız Tatas Pandelie'yi sayıyla yenmiştir (Grekoromende 6 Galibiyet Aldık. (1956, Mayıs 30). Hürriyet Gazetesi, s.5, sü. 2). Dursun Ali Erbaş üçüncü turda Saarlı Heinz Simon'u sayıla (Grekoromende Dünya Kupasını 2,5 Puanla Kaybettik. (1956, Haziran 1). Cumhuriyet Gazetesi, s.5, sü.3-4) ve final müsabakasinda Macar Boranya'yı tuşla yenmiş ve 1956 Dünya Kupası'nda şampiyon olmuştur (Grekoromende Dünya İkinciliğini Kazandık. (1956, Haziran 1) Hürriyet Gazetesi, s. 5, sü. 3-4). 52 kg'da sıralama aşağıdaki şekilde gerçekleşmiştir (Grekoromende Dünya Kupasinı 2,5 Puanla Kaybettik. (1956, Haziran 1). Cumhuriyet Gazetesi, s.5, sü.3-4).

Tablo 11. 1956 Dünya Kupası Grekoromen Stil $52 \mathrm{~kg}$ Madalya Siralamas1

\begin{tabular}{lll}
\hline Siralama & Adı Soyadı & Ülke \\
\hline 1 & Dursun Ali Erbaş & Türkiye \\
2 & Istvan Baranya & Macaristan \\
3 & Heinz Simon & Saar \\
\hline
\end{tabular}

1956 Dünya Kupası 57 kg grekoromen stilde mücadele eden Türk güreşçi Yaşar Y1lmaz, birinci turda Suriyeli Muhammed Elsese'i sayıla (Birinci Dünya Kupası Güreş Şampiyonası $\mathrm{Bu}$ Gece Sona Eriyor. (1956, Mayıs 31). Cumhuriyet Gazetesi, s.6, sü.4-8) ve ikinci turda Misırlı Nebil Suudi'yi tuşla yenmiştir (Spor Haberleri. (1956, Mayıs 30). Hürriyet Gazetesi, s.6, sü. 1-8). Yaşar Yılmaz üçüncü turda Romen Francisco Horvath'1 tuşla (Grekoromende Dünya İkinciliğini Kazandik. (1956, Haziran 1) Hürriyet Gazetesi, s. 5, sü. 3-4) ve final müsabaksında Bulgar Dinko Petrov'u sayıyla yenerek 1956 Dünya Kupası'nda şampiyon olmuştur (Grekoromende Dünya İkinciliğini Kazandık. (1956, Haziran 1) Hürriyet Gazetesi, s. 5, sü. 3-4). 57 kg'da sıralama aşağıdaki şekilde gerçekleşmiştir (Grekoromende Dünya Kupasinı 2,5 Puanla Kaybettik. (1956, Haziran 1). Cumhuriyet Gazetesi, s.5, sü.3-4).

Tablo 12. 1956 Dünya Kupası Grekoromen Stil $57 \mathrm{~kg}$ Madalya Siralaması

\begin{tabular}{lll}
\hline Siralama & Adı Soyadı & Ülke \\
\hline 1 & Yaşar Yılmaz & Türkiye \\
2 & Dinko Petrov & Bulgaristan \\
3 & Francisco Horvath & Romanya \\
\hline
\end{tabular}

1956 Dünya Kupası 62 kg grekoromen stilde mücadele eden Türk güreşçi Osman Kambur, birinci turda Fransız Jalabert Rene'yi tuşla (Birinci Dünya Kupası Güreş Şampiyonası Bu Gece Sona Eriyor. (1956, May1s 31). Cumhuriyet Gazetesi, s.6, sü.4-8) ve ikinci turda Polonyalı Drag'1 tuşla yenmiştir (Spor Haberleri. (1956, May1s 30). Hürriyet Gazetesi, s.6, sü. 1-8). Osman Kambur üçüncü turda Rus Viladimir Stackevitch'e sayıla yenilmiş (Grekoromende Dünya İkinciliğini Kazandık. (1956, Haziran 1) Hürriyet Gazetesi, s. 5, sü. 3-4) ve final müsabakasında Macar İmre Polyak'1 sayıyla yenerek 1956 Dünya Kupası'nda ikinci olmuştur (Grekoromende Dünya İkinciliğini Kazandık. (1956, Haziran 1) Hürriyet Gazetesi, s. 5, sü. 3-4). 62 kg'da sıralama aşağıdaki şekilde gerçekleşmiştir (Grekoromende Dünya Kupasinı 2,5 Puanla Kaybettik. (1956, Haziran 1). Cumhuriyet Gazetesi, s.5, sü.3-4).

Tablo 13. 1956 Dünya Kupası Grekoromen Stil $62 \mathrm{~kg}$ Madalya Siralamas1

\begin{tabular}{lll}
\hline Siralama & Adı Soyadı & Ülke \\
\hline 1 & Viladimir Stackevitch & Rusya \\
2 & Osman Kambur & Türkiye \\
3 & Imre Polyak & Macaristan \\
\hline
\end{tabular}

1956 Dünya Kupası 67 kg grekoromen stilde mücadele eden Türk güreşçi Rıza Doğan, birinci turda Bulgar Dimitri Steyanof'u tuşla yenmiş (Birinci Dünya Kupası Güreş Şampiyonas1 Bu Gece Sona Eriyor. (1956, Mayıs 31). Cumhuriyet Gazetesi, s.6, sü.4-8) ve ikinci turda Polonyalı Gencik'e sayıla yenilmiştir (Spor Haberleri. (1956, Mayıs 30). Hürriyet Gazetesi, s.6, sü. 1-8). Rıza Doğan üçüncü turda Finlandiyalı Lehtonen Kyosti'e sayılla yenildikten sonra final müsabakasında Rus Vladimir Rossino'ya kaburgasinda var olan sakatlığı nedeniyle yenilmiş ve 1956 Dünya Kupası'nda üçüncü olmuştur (Grekoromende Dünya İkinciliğini Kazandık. (1956, Haziran 1) Hürriyet Gazetesi, s. 5, sü. 3-4). $67 \mathrm{~kg}$ 'da sıralama aşağıdaki şekilde gerçekleşmiştir (Grekoromende Dünya Kupasinı 2,5 Puanla Kaybettik. (1956, Haziran 1). Cumhuriyet Gazetesi, s.5, sü.3-4). 
Tablo 14. 1956 Dünya Kupas1 Grekoromen Stil 67 kg Madalya Siralamas1

\begin{tabular}{lll}
\hline Siralama & Ad1 Soyadı & Ülke \\
\hline 1 & Vladimir Rossino & Rusya \\
2 & Lehtonen Kyosti & Finlandiya \\
3 & Riza Doğan & Türkiye \\
\hline
\end{tabular}

1956 Dünya Kupası 73 kg grekoromen stilde mücadele eden Türk güreş̧̧i Mithat Bayrak, birinci turda Suriyeli Riyad Nassarani'yi tuşla (Birinci Dünya Kupası Güreş Şampiyonası Bu Gece Sona Eriyor. (1956, May1s 31). Cumhuriyet Gazetesi, s.6, sü.4-8) ve ikinci turda Polonyalı Kuczynski'i tuşla yenmiştir (Dün Gece Grekoromen Güreșlerde 6 Galibiyet 2 Yenilgi Ald1k. (1956, Mayıs 30). Hürriyet Gazetesi, s.1, sü. 3-5). Mithat Bayrak üçüncü turda Romen Marin Belusica'y1 sayıyla ve final müsabakalarında Finlandiyalı Veikko Rantanen'i sayıyla yenmesine karşın fena puanlar neticesinde Dünya Kupası'nda ikinci olmuştur (Grekoromende Dünya İkinciliğini Kazandık. (1956, Haziran 1) Hürriyet Gazetesi, s. 5, sü. 3-4). 73 kg'da sıralama aşağıdaki şekilde gerçekleşmiştir (Grekoromende Dünya Kupasını 2,5 Puanla Kaybettik. (1956, Haziran 1). Cumhuriyet Gazetesi, s.5, sü.3-4).

Tablo 15. 1956 Dünya Kupası Grekoromen Stil $73 \mathrm{~kg}$ Madalya Siralamas1

\begin{tabular}{lll}
\hline Siralama & Adı Soyadı & Ülke \\
\hline 1 & Viladimir Maneev & Rusya \\
2 & Mithat Bayrak & Türkiye \\
3 & Veikko Rantanen & Finlandiya \\
\hline
\end{tabular}

1956 Dünya Kupası 79 kg grekoromen stilde mücadele eden Türk güreşçi İsmet Atlı birinci turda Macar Gurics Gyöygy'yi sayıyla (Grekoromende 6 Galibiyet Aldık. (1956, Mayıs 30). Hürriyet Gazetesi, s.5, sü. 2) ve ikinci turda Finlandiya'dan Munkari'yi sayıyla yenmiştir (Geceki Güreşler. (1956, Mayıs 31), Yeni İstanbul Gazetesi, s.1, sü. 57). İsmet Atlı üçüncü turda Yugoslav Branco Simic'i sayıyla yenmiş (Dünkü Güreşlerin Hepsini Kazandık. (1956, Mayıs 31). Dünya Gazetesi, s.6, sü.1-8) ve dördüncü turda Rus Giwi Kartosija'yı'yi sayıyla yenilerek Dünya Kupası'nda dördüncü olmuştur. 79 kg'da sıralama aşağıdaki şekilde gerçekleşmiştir (Grekoromende Dünya Kupasını 2,5 Puanla
Kaybettik. (1956, Haziran 1). Cumhuriyet Gazetesi, s.5, sü.3-4).

Tablo 16. 1956 Dünya Kupası Grekoromen Stil $79 \mathrm{~kg}$ Madalya Siralaması.

\begin{tabular}{lll}
\hline Siralama & Ad1 Soyadı & Ülke \\
\hline 1 & Giwi Kartosija & Rusya \\
2 & Branco Simic & Yugoslavya \\
3 & Horst Hess & Almanya \\
4 & İsmet Atlı & Türkiye \\
\hline
\end{tabular}

$87 \mathrm{~kg}$ grekoromen stilde mücadele eden Türk güreşçi Adil Atan birinci turu güreş yapmadan geçmiş (Grekoromende 6 Galibiyet Aldık. (1956, Mayıs 30). Hürriyet Gazetesi, s.5, sü. 2), ikinci turda İtalyan Adelma Bulgarelli'yi sayıyla yenmiştir (Dünkü Güreşlerin Hepsini Kazandık. (1956, Mayıs 31). Dünya Gazetesi, s.6, sü.1-8). Adil Atan üçüncü turda Rus Cherbakov'a sayıyla (Bizim Güreşler Nasıl Oldu. (1956, Haziran 2). Dünya Gazetesi, s.6, sü.6-8) ve dördüncü turda Bulgar Sirakov Atanasov Petko'ya sayıla yenilerek Dünya Kupası'nda dördüncü olmuştur. 87 kg'da sıralama aşağıdaki şekilde gerçekleşmiştir (Grekoromende Dünya Kupasını 2,5 Puanla Kaybettik. (1956, Haziran 1). Cumhuriyet Gazetesi, s.5, sü.3-4).

Tablo 17. 1956 Dünya Kupası Grekoromen Stil $87 \mathrm{~kg}$ Madalya Siralaması

\begin{tabular}{lll}
\hline Siralama & Ad1 Soyadı & Ülke \\
\hline 1 & Cherbakov & Rusya \\
2 & Sirakov Atanasov & Bulgaristan \\
& Petko & \\
3 & Gyula Kovacs & Macaristan \\
4 & Adil Atan & Türkiye \\
\hline
\end{tabular}

Ağır sıklet grekoromen stilde mücadele eden Türk güreşçi Hamit Kaplan birinci turda Rus Johannes Kotkas ile mücadele etmiş hakem kararıyla sayıyla yenilmiş (Grekoromende 6 Galibiyet Aldik. (1956, Mayıs 30). Hürriyet Gazetesi, s.5, sü. 2) ve ikinci turda Polonyalı Sosnoweld'i sayıyla yenmiştir (Dünkü Güreşlerin Hepsini Kazand1k. (1956, May1s 31). Dünya Gazetesi, s.6, sü.1-8). Hamit Kaplan üçüncü turda Yugoslav Graslj Anton'u tuşla (Grekoromen Güreşte Dünya İkincisi Olduk. (1956, Haziran 1). Hürriyet Gazetesi, s.1, sü. 7-8) ve finalde Bulgar Jussein Mehmedov'u sayıyla yenmiş ve Dünya Kupası'nda ikinci olmuştur (Grekoromende Dünya İkinciliğini Kazandık. 
(1956, Haziran 1) Hürriyet Gazetesi, s. 5, sü. 3-4). Ağır sıklette sıralama aşağıdaki şekilde gerçekleşmiştir (Grekoromende Dünya Kupasinı 2,5 Puanla Kaybettik. (1956, Haziran 1). Cumhuriyet Gazetesi, s.5, sü.3-4).

Tablo 18. 1956 Dünya Kupası Grekoromen Stil Ağır Sıklet Madalya Siralaması

\begin{tabular}{lll}
\hline Siralama & Adı Soyadı & Ülke \\
\hline 1 & Johannes Kotkas & Rusya \\
2 & Hamit Kaplan & Türkiye \\
3 & Jussein Mehmedov & Bulgaristan \\
\hline
\end{tabular}

1956 Dünya Kupası grekoromen güreş müsabakaları sonucunda Türkiye 26,5 puanla ikinci olurken, ülke puan sıralaması aşağıdaki şekilde gerçekleşmiştir (Grekoromen Güreşte Dünya İkincisi Olduk. (1956, Haziran 1). Hürriyet Gazetesi, s.1, sü. 7-8)

Tablo 19. 1956 Dünya Kupası Grekoromen Stil Müsabakaları Sonrası Oluşan Ülke Puan Siralamasi.

\begin{tabular}{lll}
\hline Sira & Ülke & Puan \\
\hline 1 & Rusya & 39 \\
2 & Türkiye & 36,5 \\
3 & Bulgaristan & 20 \\
4 & Macaristan & 14 \\
5 & Finlandiya & 14 \\
6 & Yugoslavya & 13 \\
7 & Romanya & 10 \\
8 & Almanya & 5,5 \\
9 & Misir & 4 \\
9 & Saar & 4 \\
10 & Polonya & 3 \\
10 & İsviçre & 3 \\
13 & Fransa & 1,5 \\
14 & Italya & 1 \\
15 & Lübnan & 0,5 \\
\hline
\end{tabular}

\section{TARTIŞMA ve SONUÇ}

25-31 Mayıs 1956 tarihleri arasinda İstanbul'da düzenlenen Dünya Kupası serbest ve grekoromen stil müsabakalarına Avusturya, Belçika, Bulgaristan, Mısır, Finlandiya, Fransa, Batı Almanya, Macaristan, İran, İtalya, Japonya, Lübnan, Hollanda, Pakistan, Polonya, Romanya, Saarland, Sovyet Birliği, İsviçre, Suriye, Türkiye, Birleşik Arap Emirlikleri, Birleşik Krallık, Yemen, Yugoslavya ve Türkiye'den toplam 150 güreşçi katılmıştır. Türkiye, serbest stilde kazandığı altı altın ve iki bronz madalya ile serbest stilde birinci, grekoromen stilde kazandığ i iki altın, üç gümüş, bir bronz ve iki dördüncülükle ikinci olarak şampiyonayı tamamlamıştır. 1956 Dünya Kupası müsabakaları hem Türk güreş millî takımlarının başarısı hem de Dünya Kupaları tarihinde yapılan ilk şampiyona olması ve İstanbul'da düzenlenmesi açısından son derece önemli bir organizasyon olarak görülmektedir. 1956 Dünya Kupası elde edilen başarılar ve 1956 Melbourne Olimpiyat Oyunları öncesi önemli bir hazırlık firsat1 olmasının yanı sıra Türk güreş yapılanması için bazı sorgulamaların yapıldığ organizasyon olarakta değerlendirilmektedir. Şöyleki, bu organizasyondan sonra serbest ve grekoromen takımlarını oluşturan güreşlerin farklı olması gerektiği, aynı güreşçinin serbest stilden sonra grekoromen stil güreşlerine katılmasının sakıncalı olduğu, aynı şekilde serbest ve grekoromen güreş takımlarının antrenörlerinin de farklı olmasının sporcuların organizasyonlara daha iyi hazırlanmas1 açısından önemli olacağı görüşü ortaya atılmıştır.

\section{KAYNAKÇA}

Birinci Dünya Kupası Güreş Şampiyonası Bu Gece Sona Eriyor. (1956, 05, 31). Cumhuriyet Gazetesi. 6, 4-8.

Bizim Güreşler Nasıl Oldu. (1956, 06, 02). Dünya Gazetesi. 6, 6-8.

Dün Gece Grekoromen Güreşlerde 6 Galibiyet 2 Yenilgi Aldık. (1956, 05, 30). Hürriyet Gazetesi. 1, 3-5.

Dünkü Güreşlerde 12 Galibiyet Aldık. (1956, 05, 27). Cumhuriyet Gazetesi. 5, 2-5.

Dünkü Güreşlerin Hepsini Kazandik. (1956, 05, 31). Dünya Gazetesi. 6, 1-8.

Dünya Kupası. (1956, 05, 26). Milliyet Gazetesi. 6, 1-7.

Dünya Kupası Güreşleri Başladı. (1956, 05, 26). Cumhuriyet Gazetesi. 6, 1-8.

Dünya Güreş Federasyonu. (2020, 22 Ekim). Dünya Kupası Şampiyonaları Sonuçları. Erişim adresi: https://unitedworldwrestling.org/database.

Geceki Güreşler. (1956, 05, 31), Yeni İstanbul Gazetesi. 1, 5-7.

Gündüz Yapılan Güreşler. (1956, 05, 26). Hürriyet Gazetesi. 6, 1-8.

Grekoromende 6 Galibiyet Ald1k. (1956, 05, 30). Hürriyet Gazetesi. 5, 2. 
Grekoromende Dünya Kupasını 2,5 Puanla Kaybettik. (1956, 06, 01). Cumhuriyet Gazetesi. 5, 3-4.

Grekoromen Güreşte Dünya İkincisi Olduk. (1956, 06, 01). Hürriyet Gazetesi. 1, 7-8.

Grekoromende Dünya İkinciliğini Kazandık. (1956, 06, 01). Hürriyet Gazetesi. 5, 3-4.

Grekoromen Şampiyonası Bugün 16:30'da Başlıyor. (1956, 05, 29). Dünya Gazetesi. 6, 1-8.

Güreş. (1956, 05, 26). Hürriyet Gazetesi. 6, 2-6.

Güreş Ekibinin Tespit Tarihi Henüz Belli Değil. (1956, 05, 17). Milliyet Gazetesi. 6, 5-8.

Güreş Müsabakalarının 12 Dakikaya İnmesi Teklifimizi Dün Teknik Komite Müsait Karşılad1. (1956, 05, 23). Hürriyet Gazetesi. 6, 4-5.

Misır ve Bulgar Güreşçileri Geliyor. (1956, 05, 08). Milliyet Gazetesi. 6, 3.

Milli Güreş Kampında Son Hazırlık. (1956, 05, 15). Milliyet Gazetesi. 6, 8.

Millî Güreş Takımımız Nihayet Tespit Edildi. (1956, 05, 22). Milliyet Gazetesi. 6, 1-6.

Serbest Güreşte Takımımız Dünya Şampiyonluğunu Aldı. (1956, 05, 28). Hürriyet Gazetesi. 1, 5-8.

Spor Haberleri. (1956, 05, 28). Hürriyet Gazetesi. $6,1-8$.

Spor Haberleri. (1956, 05, 30). Hürriyet Gazetesi. $6,1-8$.

Şampiyonluğu Garantiledik. (1956, 05, 27). Milliyet Gazetesi. 6, 2-6.

Takımların Kadroları Dün Tespit Edildi. (1956, 05, 19). Milliyet Gazetesi. 6, 6-8.

Uluslararası Güreş Şampiyonaları Sonuçları. (2020, 12 Ekim). 1956 Dünya Kupası Sonuçları. Erişim adresi: https://www.wikiwand.com/en/1956_Wre stling_World_Cup. 